"Mircea cel Batran" Naval Academy Scientific Bulletin, Volume XIX - 2016 - Issue 1

Published by "Mircea cel Batran" Naval Academy Press, Constanta, Romania // The journal is indexed in:

PROQUEST / DOAJ / DRJI / JOURNAL INDEX / I2OR / SCIENCE LIBRARY INDEX / Google Scholar / Crossref /

Academic Keys / ROAD Open Access / OAJI / Academic Resources / Scientific Indexing Services / SCIPIO

\title{
USING COTS COMPONENTS IN MILITARY COMMUNICATIONS SYSTEMS - TESTING AND EVALUATION
}

\author{
Dan FOSTEA ${ }^{1}$ \\ Liviu COŞEREANU² \\ Laurentiu DUMITRU3 \\ Ciprian RACUCIU 4 \\ ${ }^{1}$ Scientific researcher III, Ph.D. Cand., Maj., Eng., Military Equipment and Technologies Research Agency, \\ Bucharest \\ ${ }^{2}$ Scientific researcher II, Ph.D. , Col., Eng., Military Equipment and Technologies Research Agency, \\ Bucharest \\ ${ }^{3}$ Ph.D. Cand., Eng.,, Military Technical Academy, Bucharest \\ ${ }^{4}$ Prof. Univ. Eng. Ph.D., Titu Maiorescu University, Bucharest
}

\begin{abstract}
The civilian/commercial market in the field of communications and information has nowadays a fulminate evolution. This evolution is based on satisfying the increasing need of a public that is already familiarised with the advantages of the modern technology.

The avalanche of the innovations released on the market created also the necessity for interoperability between different providers. This is mainly because the evolution tends to be unitary. Consequently, there emerged manufactures specialised in certain components that can be integrated in different personalised systems. Furthermore, the laws enforced in UE and not only imposed a series of standards helping the interoperability.

Those standards define certain technical performances for different products. These imposed performances together with the more performing modern technology made these commercial products (Commercial Of The Shelf - COTS) more and more attractive for the military, especially in the field of communications and information.

This paper will present the possibilities of using COTS' products as part of complex military communications systems. Testing and evaluation of such components aims for maintaining the tactical and technical characteristics of the system while using commercial equipments.

As a case study, we will follow the use of small components as FPGA to larger systems as a Satellite. All those regarded through the process of testing and evaluation in order to obtain not only a fail resistant system but also a technical superior one.
\end{abstract}

Key words: Informatics, Testing-and-evaluation, Communications, Space as critical infrastructure

\section{Introduction}

Commercial equipment is more and more present in military systems. This thing was not an option some years ago due to the big difference between military and civilian requirements.

Nowadays, not only basic components like FPGA's are used in both commercial and military systems but also complex systems and subsystems as the ones designed for satellites.

This paper is engaging some brief analysis of the integration of such components (Commercial of The Shelf - COTS) from the testing and evaluation perspective.

\section{Objective}

In order to set the bar high and to really consider the influences of COTS in a system we are looking a complex system both as architecture and as functionalities.

It would be very nice if the testing could be objective. We can do this regarding measurements and in some cases where a well- defined standard is in place. But, unfortunately, it is quite difficult to test the functionalities of a complex system or forward more a system of systems.

We know what the product / the system and so on has to do, but we just cannot know how to prove it and it is more difficult to provide tests which are reveling all systems' characteristics.

Even if the words before describe the general purpose of automating testing a communications system this paper will describe only some steps.[1]

The view above is true the system is either military or commercial. In the case of military systems integrating commercial components the affirmation is indeed true.

\section{State-of-the-art}

Communications systems being so widely spread in many fields and having so many and diversified components the preferred testing approach is to design personalized tests and procedures. This 


\begin{abstract}
"Mircea cel Batran" Naval Academy Scientific Bulletin, Volume XIX - 2016 - Issue 1
Published by "Mircea cel Batran" Naval Academy Press, Constanta, Romania /I The journal is indexed in: PROQUEST / DOAJ / DRJI / JOURNAL INDEX / I2OR / SCIENCE LIBRARY INDEX / Google Scholar / Crossref /

Academic Keys / ROAD Open Access / OAJI / Academic Resources / Scientific Indexing Services / SCIPIO
\end{abstract}

approach can bring the desired results but implies hard work in the planning phase and long and non-standard tests [2].

There are a lot of software tools, developed for specific systems:

- Elektrobit Testing Ltd. used MathWorks tools to develop the Propsound ${ }^{\mathrm{TM}} \mathrm{CS}$, a high-resolution multidimensional radio channel measurement system;

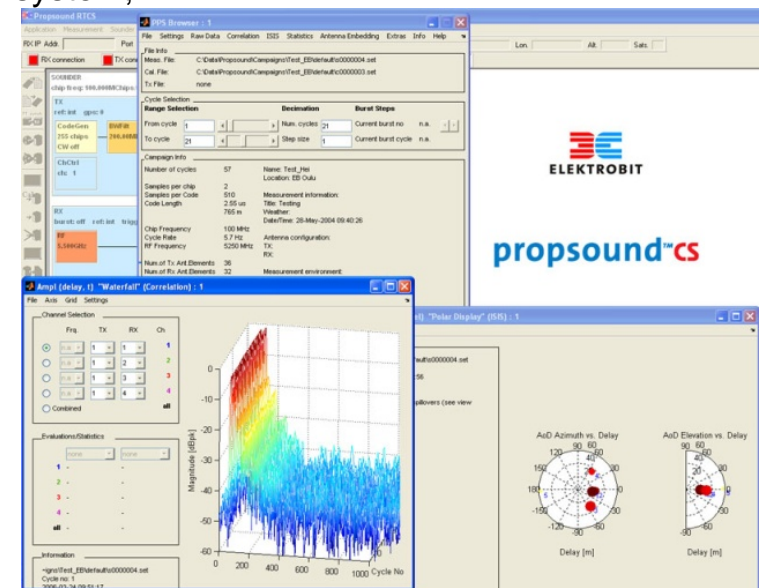

Figure 1 - Testing software developed using MathWorks[4]

The example described before is only a solution of getting tests results using an automated testing system.

To enforce the power of such examples we will present a more specific case of conducting evaluating procedures in a laboratory.

\section{Testing in laboratory conditions}

When analyzing the possibility of introducing COTS in a military systems we elaborate different studies we pull up all kinds of equations and statistics. We even do some simulation and finally we prove the concept.

In order to really present the performance of a COTS component / subsystem integrated in a military system we need to follow on the system during operation.

Some ideas:

A software computation system is necessary to be implemented in order to manage the entire procedure;

The use of different hardware may be automated by creating an platform that allows us to connect to the system;

"It is important to have a clear-cut methodology suitable for software implementation" [3].

Following those written before we will describe the procedure in place in military testing procedures, based on this procedure we will try to present a concept of an automated solution and finally we will get into details of implementation of such a solution.

\section{Testing the military systems}

Through time we had undertaken a lot of testing procedures, especially for military communications systems delivered and developed by civilian entities but not only.

First, we have to say a few words about testing approach in Romanian Ministry of National Defense. All this activities, including communications systems, are somewhat standardized by I.1004 document [6].

The objectives of the testing and evaluation process are as follows [1]:

- The rapid generation of objective information, with a high degree of accuracy, needed for the decision authority in order to establish the efficiency and the readiness of a product regarding military use.

- The identification of problems and the proposal of solution for them in order to solve the eventual deficiencies.

- The establishment of the upgrade possibilities for a certain product or system.

- $\quad$ Minimizing the risks presented in different life cycle phases.

Of course, the testing can offer help with different other problems and it is possible to implement testing activities addressing some specific issues.

\section{COTS sampled}

FPGA chips come in various forms and packages. Depending on the vendor, chip family, speed characteristics and area size, one can choose among different versions of the same chip. Xilinx offers, for normal chips, three temperature ranges: Commercial (0 to 85), Extended (0 to 100) and Industrial $(-40$ to +100$)$. When an FPGA is to be installed into a mission-critical solution, the defense-grade family can be used. It offers temperature support from -55 to +125 , anticounterfeiting features, ruggedized packaging, information assurance and anti-tamper support. In all defense-grade devices, the bitstream, which can contain secret data, can be protected with 256-bit AES encryption and HMAC/SHA-256 authentication to prevent unauthorized intrusion. The FPGA performs realtime decryption of the configuration data using an internally stored 256bit key. Radiation can cause device malfunctions through Single Event Latch-ups, Single Event Upsets, Single Event Gate Ruptures or Single Event Burnouts. Such effects can be incountered in space and in radioactive environments. To mitigate such effects, one can implement various software approaches, such as Triple Module Redundandy or it can use radiation-hardened 
"Mircea cel Batran" Naval Academy Scientific Bulletin, Volume XIX - 2016 - Issue 1

Published by "Mircea cel Batran" Naval Academy Press, Constanta, Romania // The journal is indexed in: PROQUEST / DOAJ / DRJI / JOURNAL INDEX / I2OR / SCIENCE LIBRARY INDEX / Google Scholar / Crossref /

Academic Keys / ROAD Open Access / OAJI / Academic Resources / Scientific Indexing Services / SCIPIO

chips. A radiation hardness test of a commercial Kintex chip can be found in [2]. Overall, FPGAs are highly versatile chips which can fit into a vast majority of operating environments, without increasing the costs.

As in the previous paragraph we presented some basic capabilities of FPGA's now we are turning the view some subsystems used in critical infrastructures.

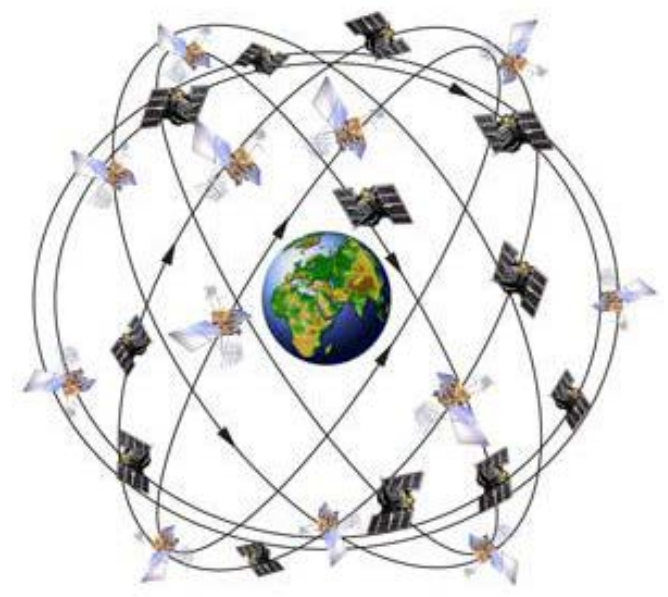

Figure $>$ GPS constellation (www.schriever.af.mil/news/story.asp?id=1232 60251)

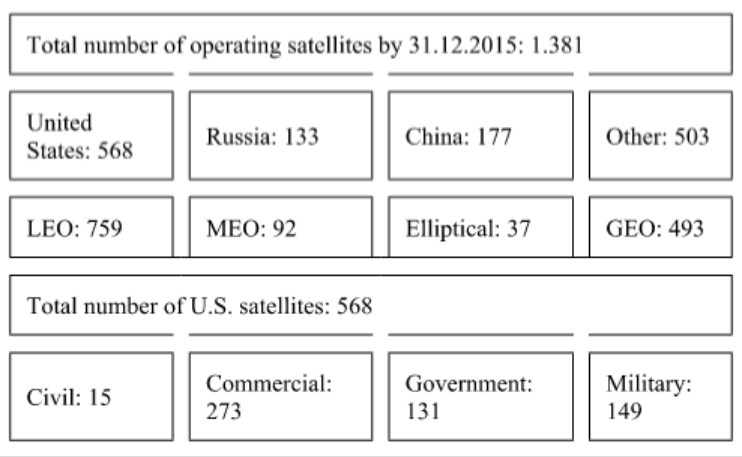

Figure 6 Total number of operating satellites[3]

To get a better grasp of the space critical infrastructure and its role as we evidence the importance of the components and subsystems involved we presented below the main components.[3]

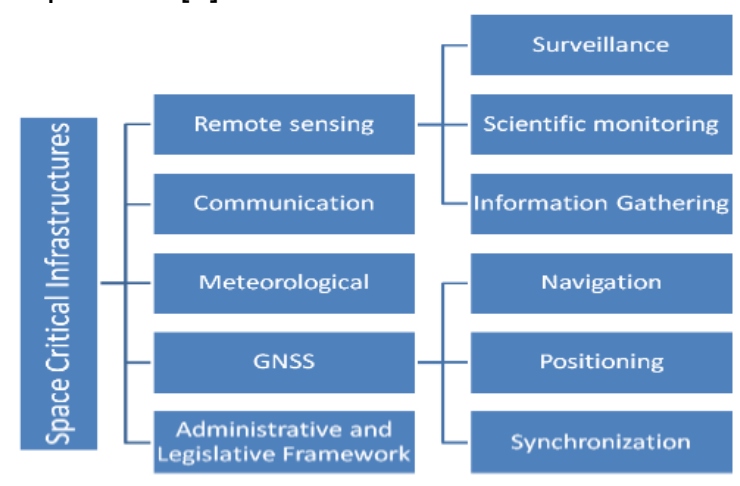

Figure 7 Space Critical Infrastructure

\section{CONCLUSIONS}

Integrating COTS elements in a military system may have its benefits not only in price range but also in performance but such an integration should be considered very attentive in order not to affect the over whole performances of the system.

COTS components like FPGA are quite the same in the commercial and military systems so they generally do not impose any limitations to the system they serve.

Another kind of COTS are the ones part of a critical infrastructure system as the space critical infrastructure. In this particular case those subsystems are recommended not only by their performances and by robustness but also by their life cycle.

ACKNOWLEDGEMENT. This paper has been financially supported by a grant of the Romanian National Authority for Science Research, CNDI-UEFISCDI, project number 197/2012.

\section{BIBLIOGRAPHY}

[1] Automating the process of testing the functionalities of complex communications systems

Scientific researcher III, Cpt., Eng. Fostea Dan

Military Equipment and Technologies Research Agency, Bucharest

Ph.D. Cand., Eng., Dumitru Laurenţiu

Military Technical Academy, Bucharest

Prof. Univ. Eng. Ph.D., Răcuciu Ciprian

Titu Maiorescu University, Bucharest

Scientific researcher III, Ph.D. Cand., Lt. col., Eng. Enache Mihai

Military Equipment and Technologies Research Agency, Bucharest 
"Mircea cel Batran" Naval Academy Scientific Bulletin, Volume XIX - 2016 - Issue 1

Published by "Mircea cel Batran" Naval Academy Press, Constanta, Romania // The journal is indexed in: PROQUEST / DOAJ / DRJI / JOURNAL INDEX / I2OR / SCIENCE LIBRARY INDEX / Google Scholar / Crossref / Academic Keys I ROAD Open Access / OAJI / Academic Resources / Scientific Indexing Services / SCIPIO

[2] Cojocariu, L. N., V. M. Placinta, and L. Dumitru. "Monitoring system for testing the radiation hardness of a KINTEX-7 FPGA." 9TH INTERNATIONAL PHYSICS CONFERENCE OF THE BALKAN PHYSICAL UNION (BPU-9). Vol. 1722. AIP Publishing, 2016.

[3] "ADVANCED TECHNIQUES FOR COMPLEX COMMUNICATIONS SYSTEMS TESTING-TEACOM",Dan Fostea, Dresmara, Brasov, 2013;

[4] Compositional Testing of Communications Systems, R. Gotzhein, F. Khendek, Report 329/2004, Department of Computer Sciences, University of Kaiserslautern, Germany, 2004, Zusammenfassung [5] http://www.mathworks.com/company/user stories/hElektrobit-Testing-Ltd.-Develops-HighResolution-Radio-Channel-Measuring-System.html, 2013-05-11

[6] "I.1004 - Instruction regarding the testing and evaluating process and the homologating process", Armaments Department/MApN, 2005 